\title{
A Jurisprudential Investigation of the Body Organ Trade
}

\author{
Reza Ali Karami ${ }^{*}$, Mohammad Reza Razzaghi², Morteza Salimi ${ }^{3}$, Mohammad Javad Maleka Ashtiyani ${ }^{3}$
}

1. Assistant Professor, Department of Theology and Islamic Studies, Payame Noor University, Tehran, Iran

2. Professor, Department of Urology, Shahid Beheshti University of Medical Sciences, Tehran, Iran

3. Master of Jurisprudence and Law of Islamic Law, Payame Noor University, Tehran, Iran

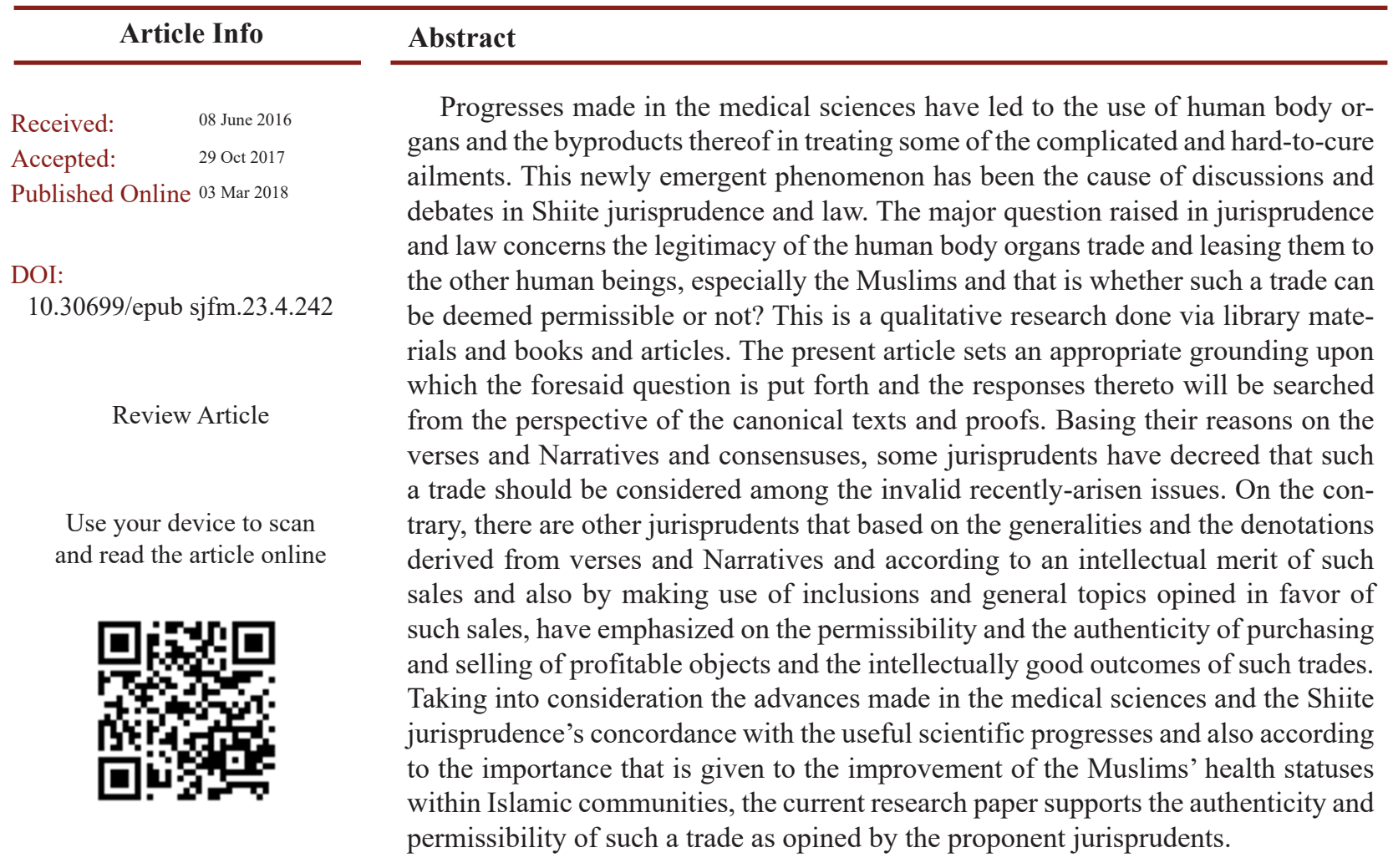

Keywords: Islamic Jurisprudence, Verdict, Organ Transplantation, Organ Trade

How to Cite This Article:

Karami A R, Razzaghi M R, Salimi M, Maleka Ashtiani M J. A Jurisprudential Investigation of the Body Organ Trade. Ir J Forensic Med. 2018;23 (4):242-250. 


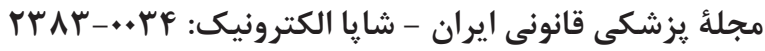

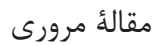

بررسى احكام فقهى -حقوقى خريد و فروش اعضاى بدن

رضاعلى كر مى ا":، محمدرضا رزاقى"، مرتضى سليمى “، محمدجواد ملكا آشتيانى"

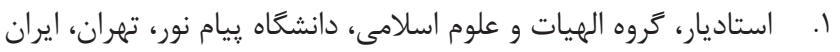

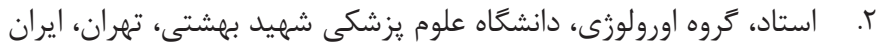

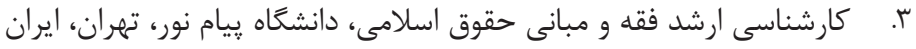

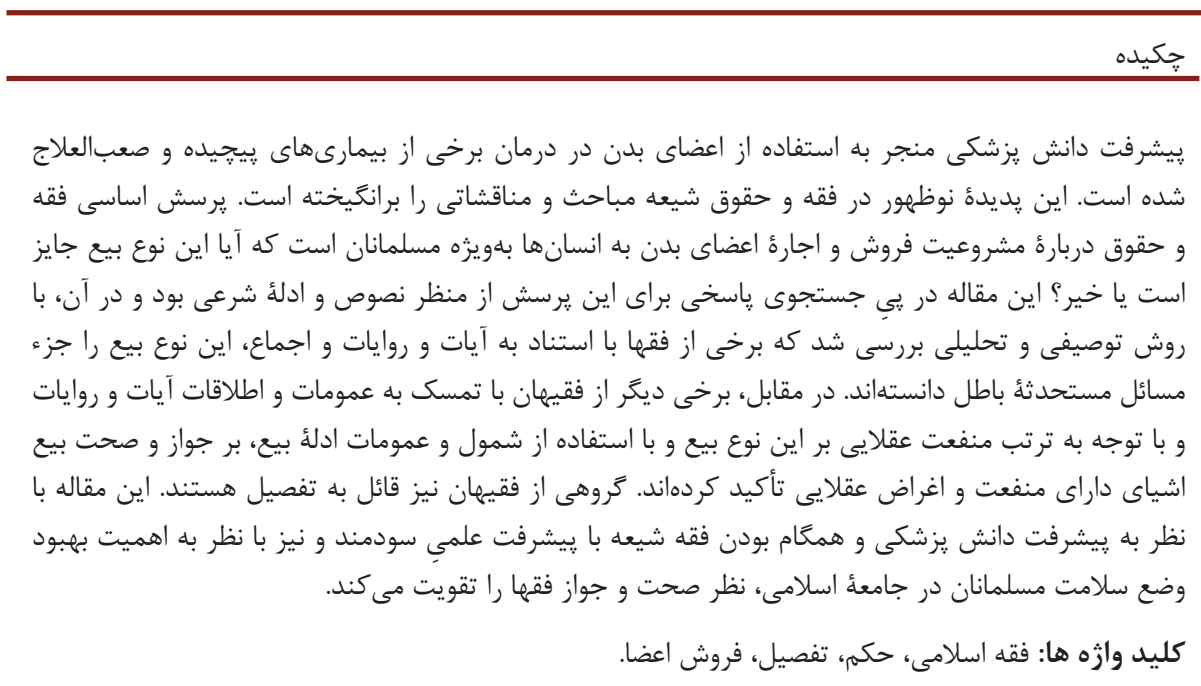

اطلاعات مقاله

$$
\begin{aligned}
& \text { تاريخ وصول: } \\
& \text { تاريخ يذيرش: } \\
& \text { انتشار آنلاين: } \\
& \text { نويسنده مسئول: } \\
& \text { رضاعلى كرمى نو } \\
& \text { يست الكترونيك: }
\end{aligned}
$$

Ra_karami@pnu.ac.ir 
جارجوب تحقيق اسنادى امكان يذير شده است. مفاهيم

\section{ا - تعريف بيع}

الف- تعريف لغوى:

كلمه بيع (داد) در لغت به معناى دادن در مقابل ستاندن

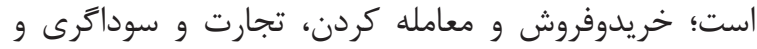

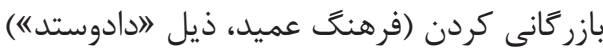

كما عن المصباح المنير: مبادله مالبdمال (F) ب- تعريف اصطلاحى: اانتقالُ عين من شَخص إلى غَيره بَعَوض مُقدر عَلَى وجه

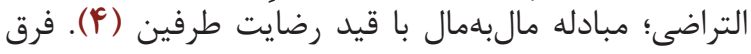
ميان تعريف لغوى و اصطلاحى، همين قيد لاتراضى" است.

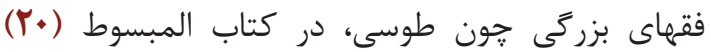

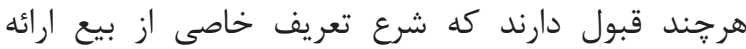

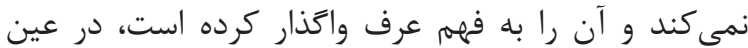

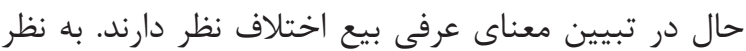

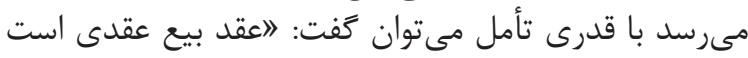

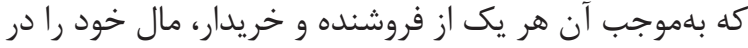

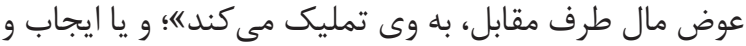

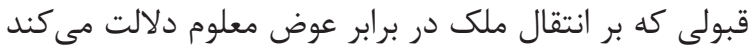

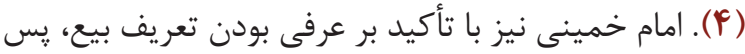

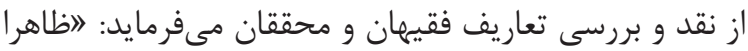

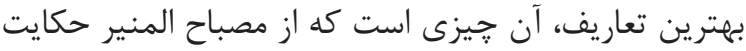

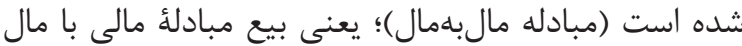

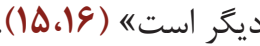

\section{ץ- تعريف اعضاى بدن}

$$
\text { الف- تعريف لغوى }
$$

"اعضو" در لغت بلمعناى اندام كردن (منتهى الارب) و جدا

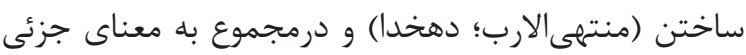

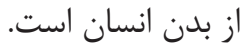

$$
\text { ب- تعريف اصطلاحى }
$$

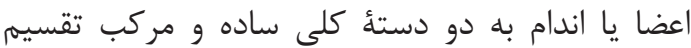

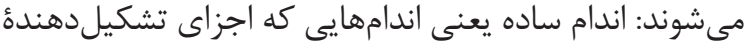

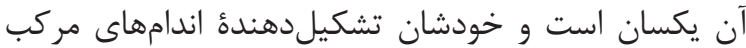

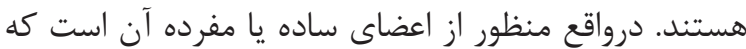

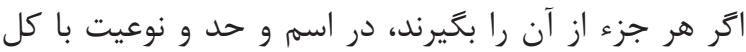

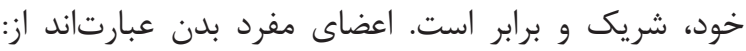

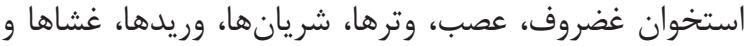

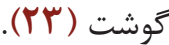

به اعضاى مختلف بدن كه از اندامهاى مفرد تشكيل

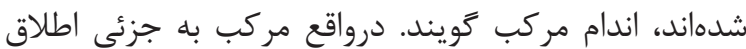

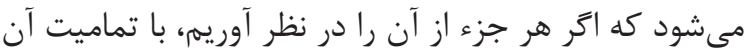

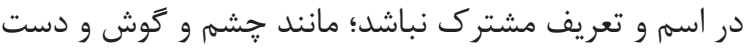

مقدمه

ييشرفت دانش بشرى در شاخههاى گَوناگون باويزه در

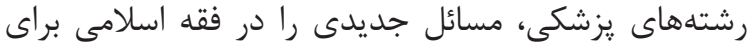

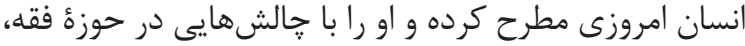

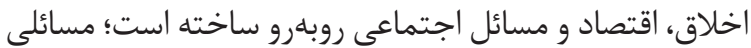

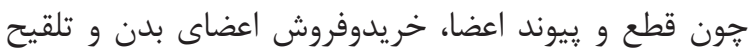

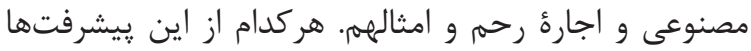

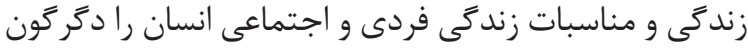

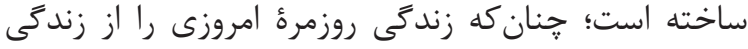

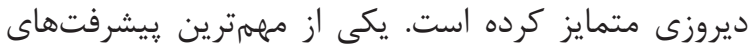

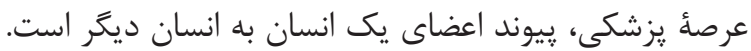

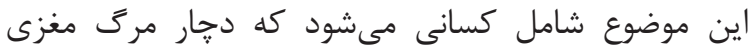

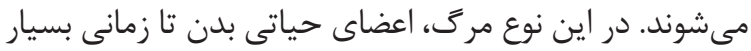

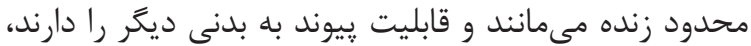

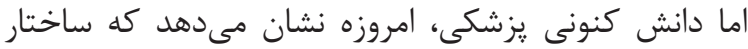

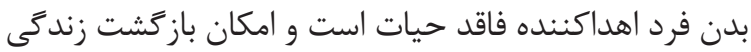

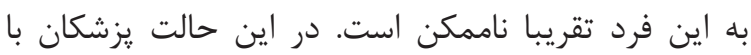

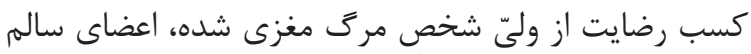

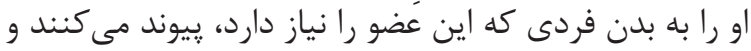

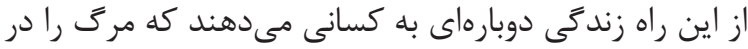
يیش جشمان خود دارند.

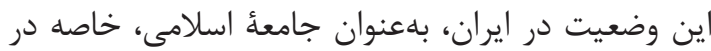

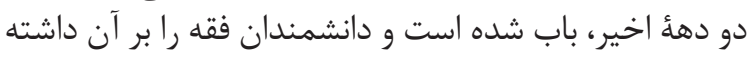

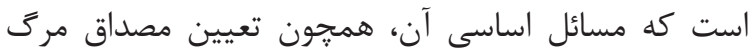

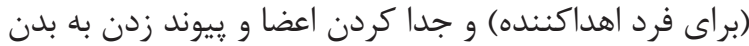

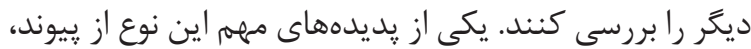

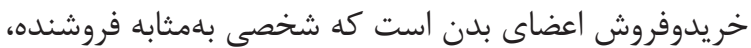

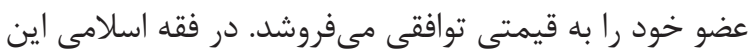

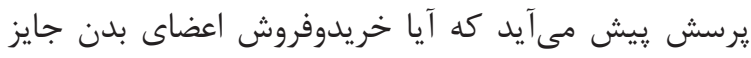

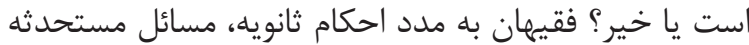

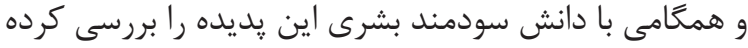

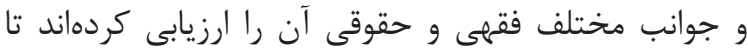

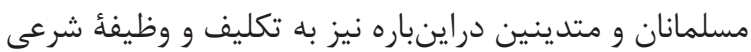

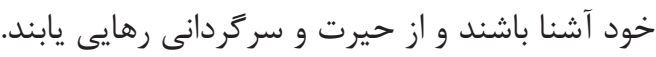
حاصل اين بررسى، مناقشات فقهى ایى بوده است كه عدهاى

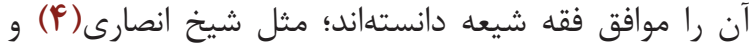

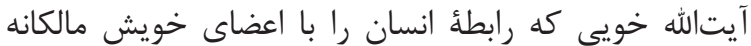

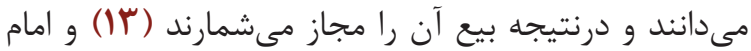

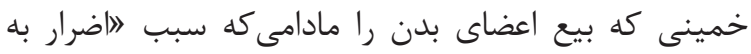

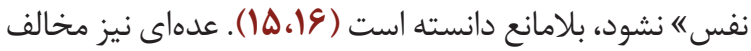

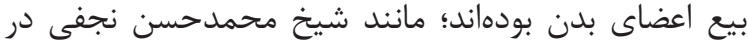

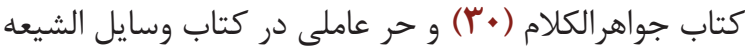

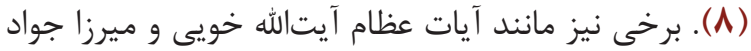

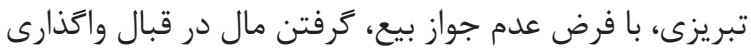

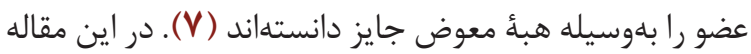

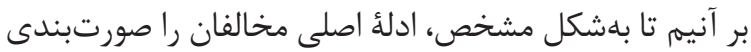

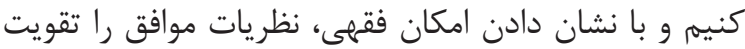

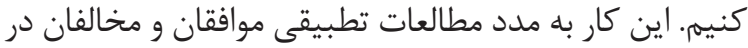


از بدنش حرام باشد؛ جه اينكه باعث نمىشود كه آن حق

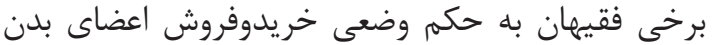

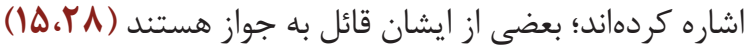

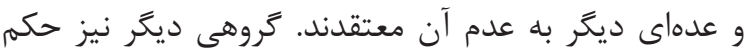

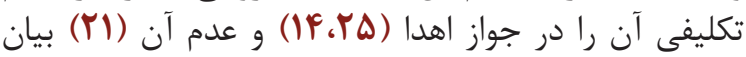

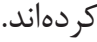

\section{وجه عقلانى و انضمامى بيع اعضا}

سالانه افراد زيادى بهدليل نارسايى يكى از اعضاى حياتى

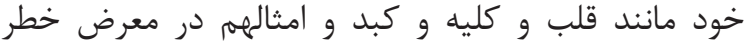

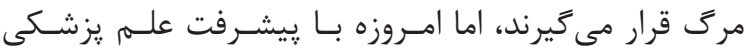

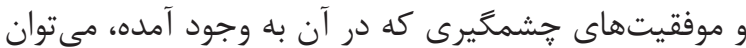

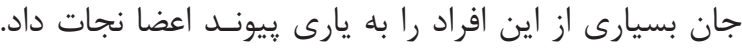

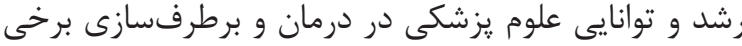

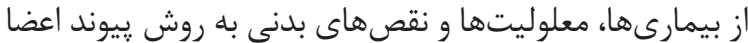

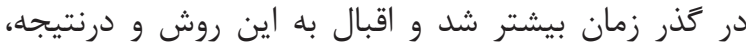

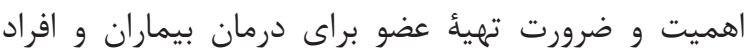
نيازمند را كانون توجه قرار داد.

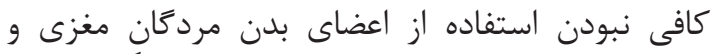

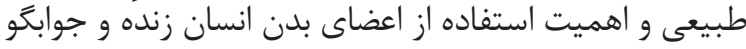

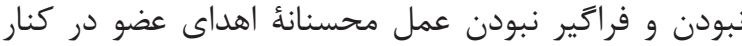

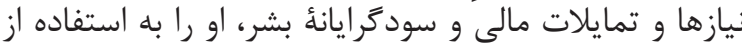

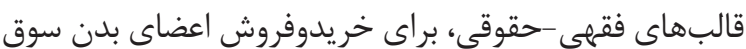

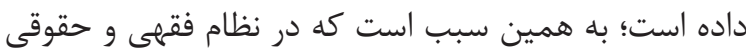

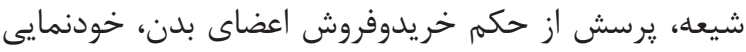

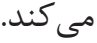

در كذشته فقيهان اسلامى موردى براى طرح موضوع

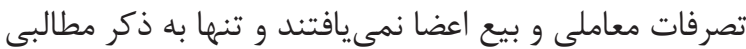

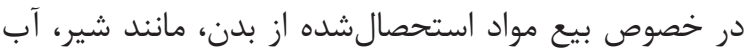

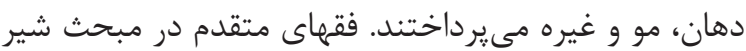

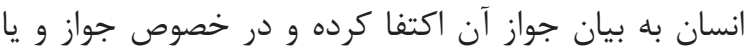

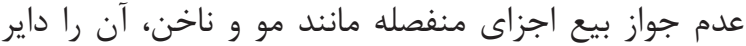

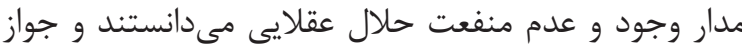

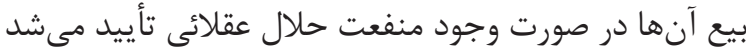

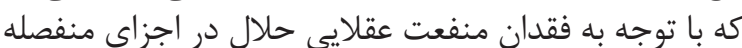

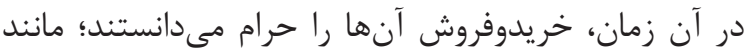

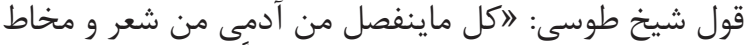

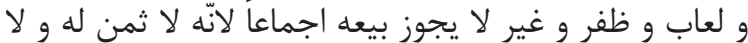

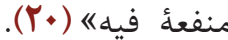

حال طبيعى است كه با مستحدثه شمرده شدن مسئلة

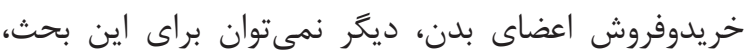

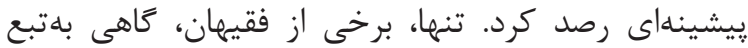

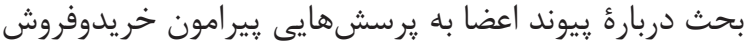

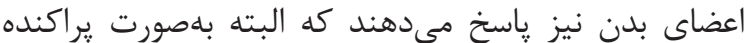

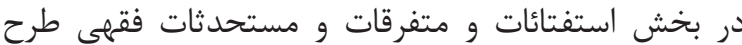

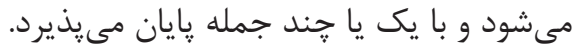
توجه به تأثير كذارى و تنقيح مبانى مشروعيت خريد و
اما اندامها ازنظر كاربردى به دو دسته تقسيم مىشوند:

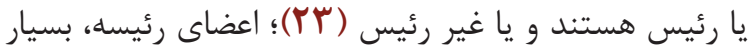

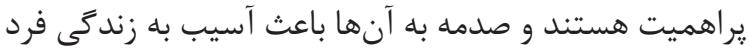

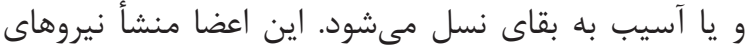

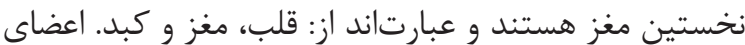

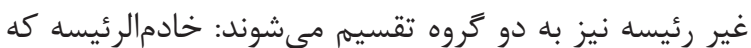

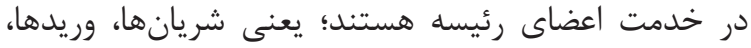

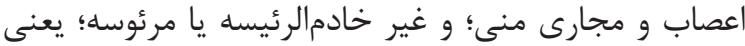

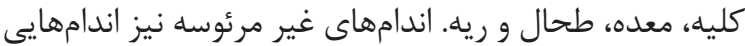

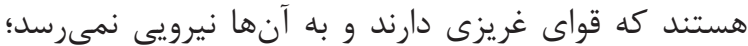

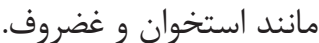

براى مثال، قلب عضو فرمانده است و عضو فرماند آندر

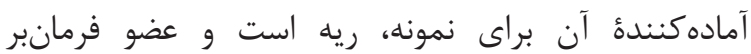

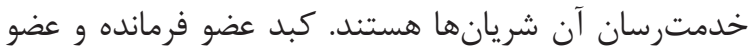

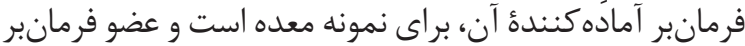

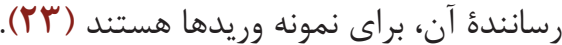

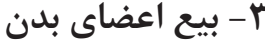

رابطؤ انسان با اعضاى بدن خويش با تعابيرى جون مالكيت

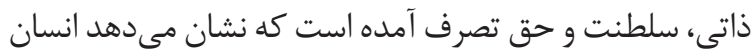

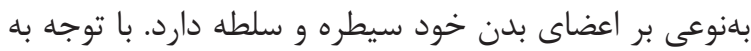

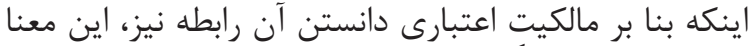

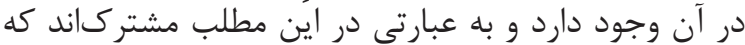

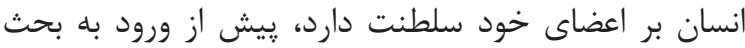

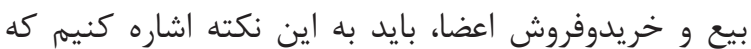

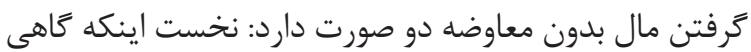

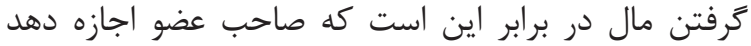

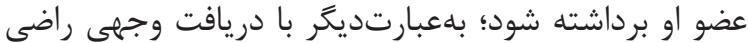

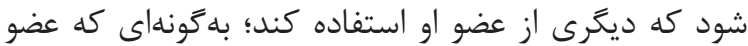

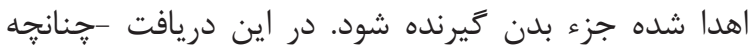

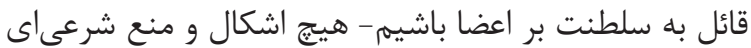

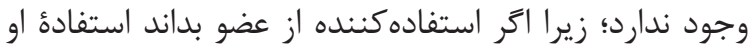

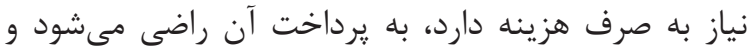

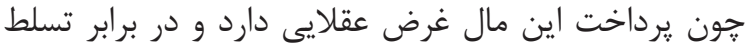

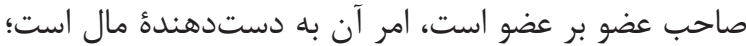

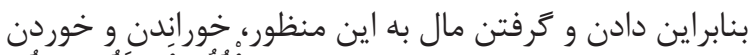

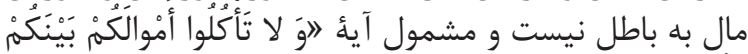

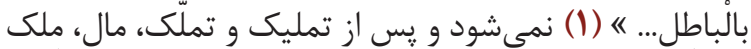

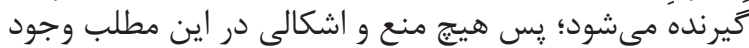

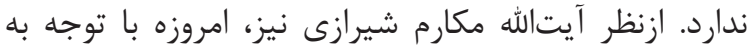

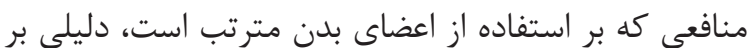

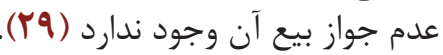

صورت دوم اينكه كاهى كرفتن مال در برابر اين است كه إنه

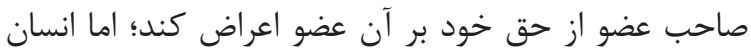

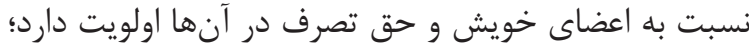

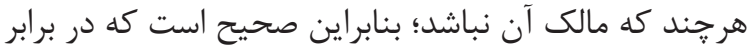

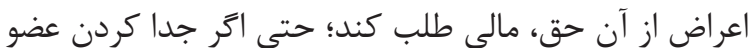




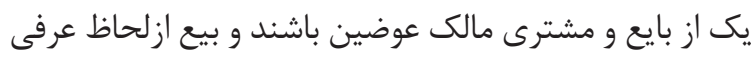

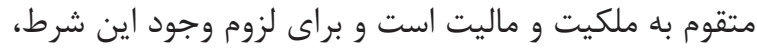

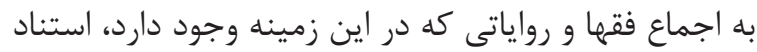

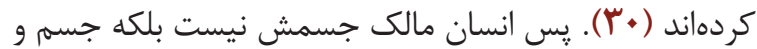

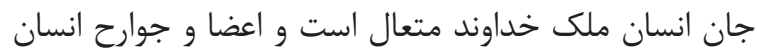

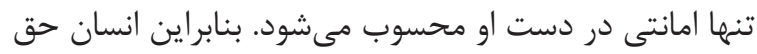

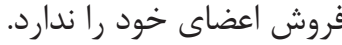

$$
\text { دليل دوم: عدم مالكيت اعضاى بدن انسان }
$$

يكى ديكر از دلايل مخالفين جواز بيع اعضاى عدم، ماليت الندان

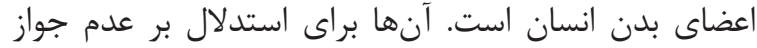

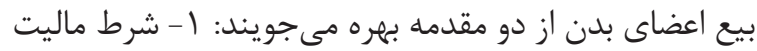

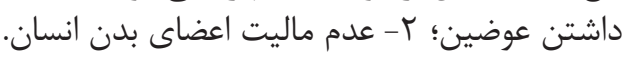

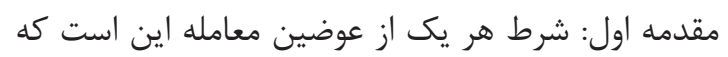

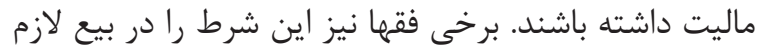

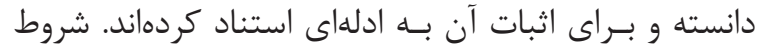

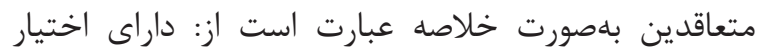

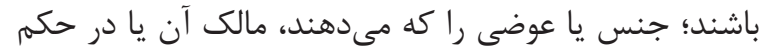

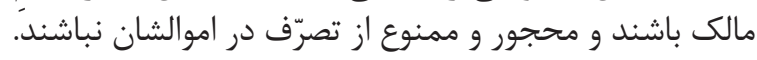

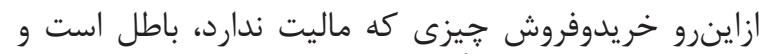

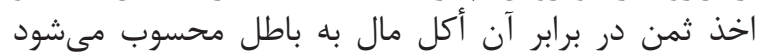

مقدمه دوم: جسم انسان و اعضاى او مال نيستند تا اينكه

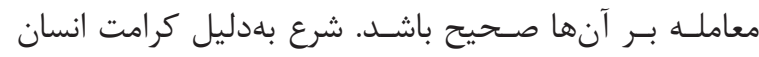

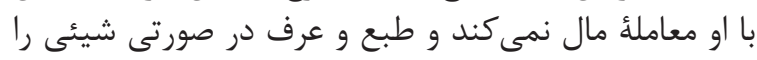

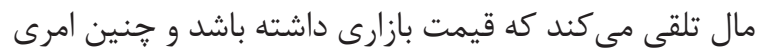

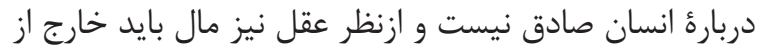

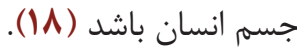

انسان حُر نه مال است و نه ملك و به به همين دليل،

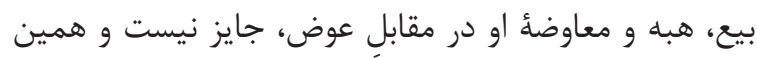

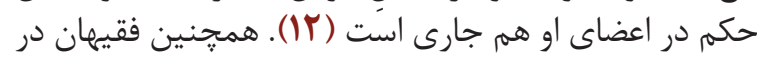

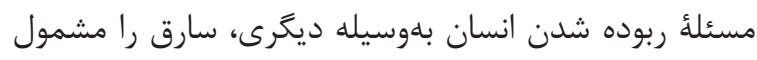

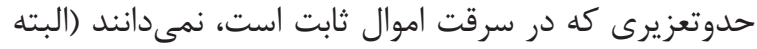

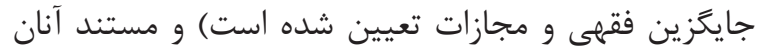

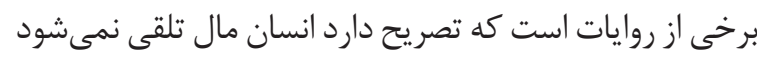

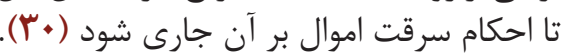

$$
\text { دليل سوم: حرمت و بطلان بيع ميته }
$$

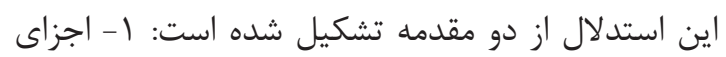

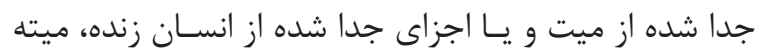

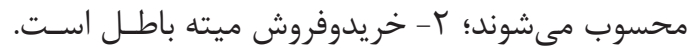

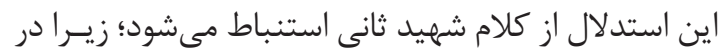

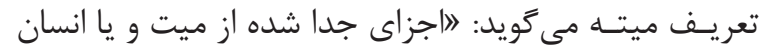

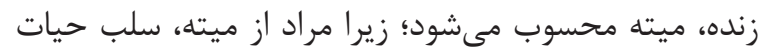

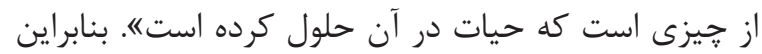

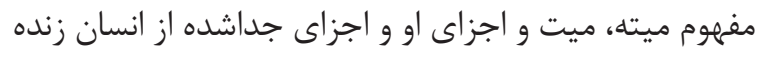

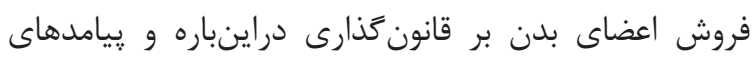

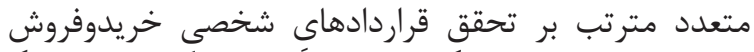

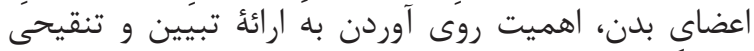

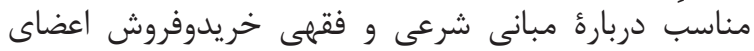

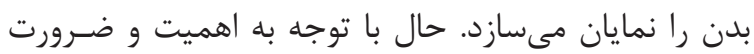

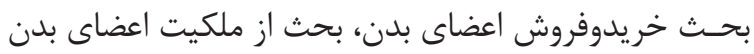

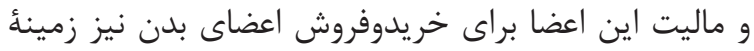

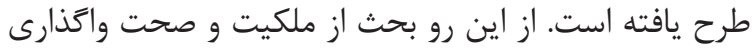

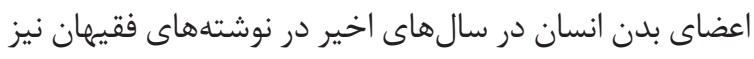

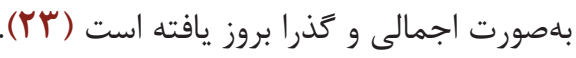

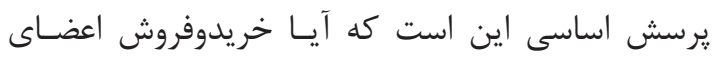

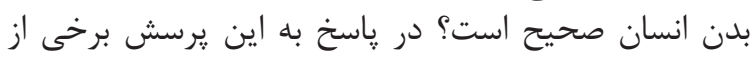

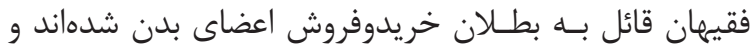

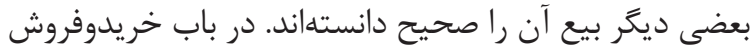
اعضاى بدن جند ديدكاه وجود دارد دارد:

ديدَاه اول: عدم جواز خريدوفروش اعضاى بدن

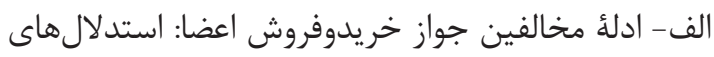

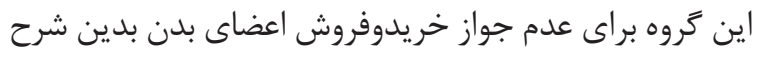

دليل اول: مالكيت نداشتن انسان نسبت به اعضاى بدنش

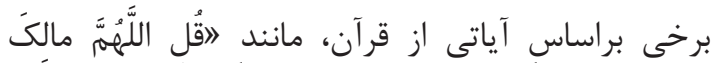

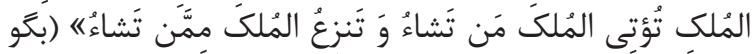

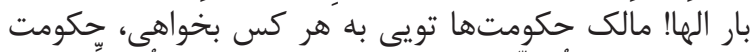

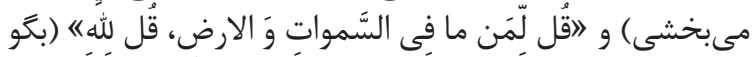

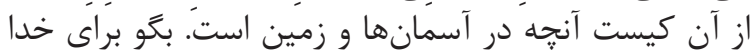

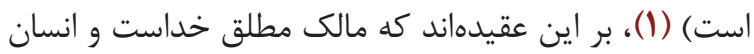

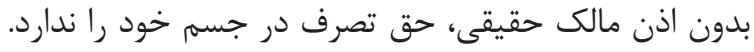

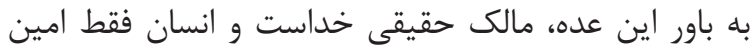

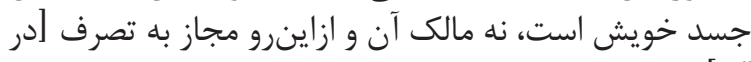

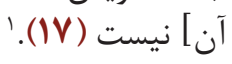

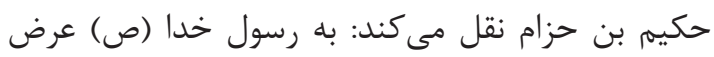

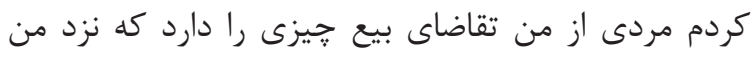

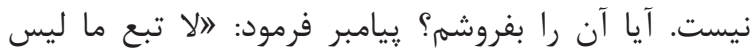

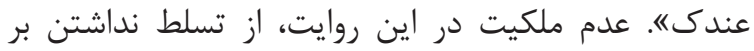

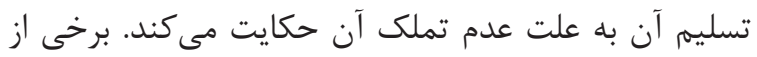

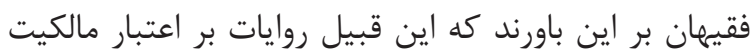

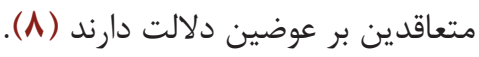

برخى اعتبار مملوكيت مبيع را در خريدوفروش مبر معتبر

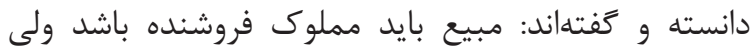

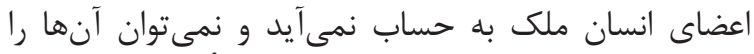

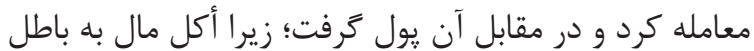

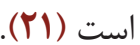

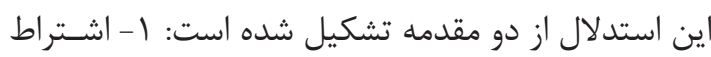

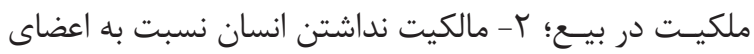
بدنش. مقدمه اول: يكى از شرايط صحت بيع اين اسـت كـه هر 


$$
\begin{aligned}
& \text { دليل اول: آيات (عمومات و اطلاقات كتاب) }
\end{aligned}
$$

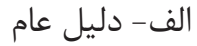

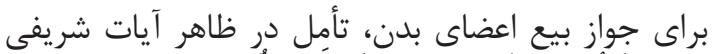

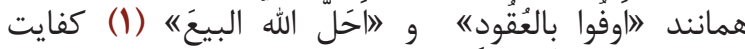

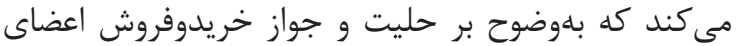

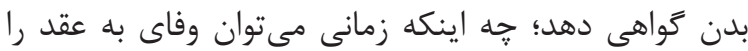

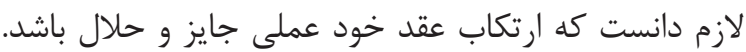

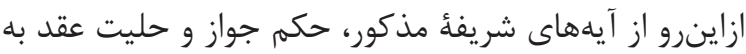

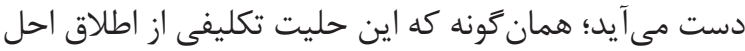

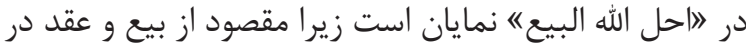

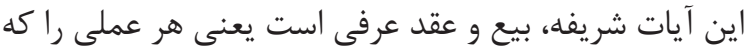

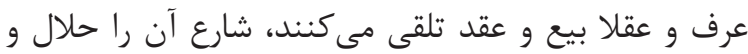

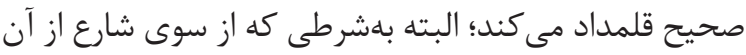

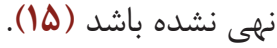

درباره اعضاى بدن بايد كفت كه عرف و عقلا، كرفتن

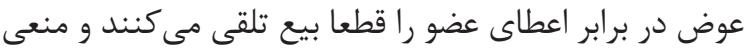

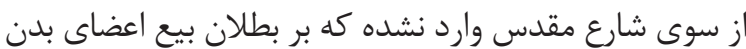

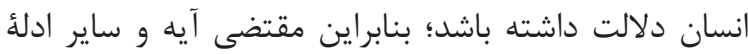

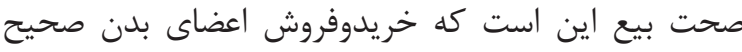

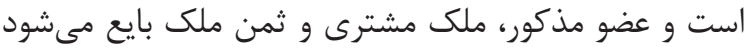

البته كَفتنى است كه در صورتى كه صاحب عضو زنده باشد،

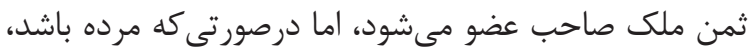

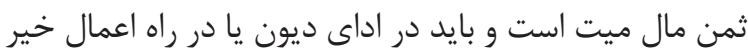

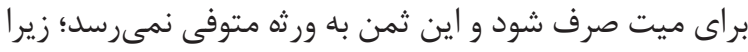

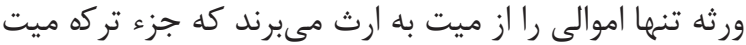

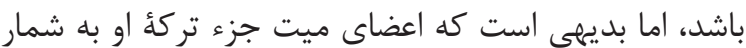

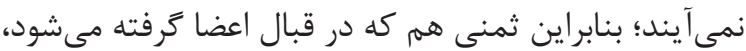

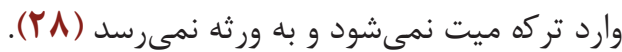

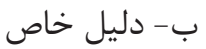

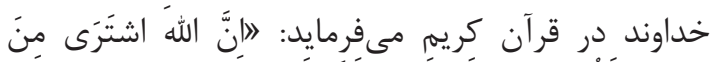

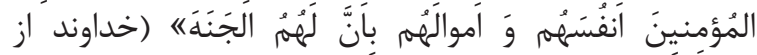

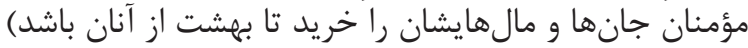

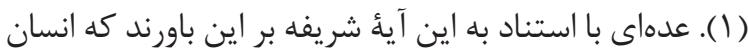

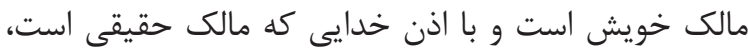

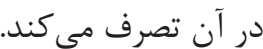

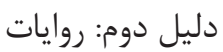

مناط صحت بيع اين است كه مبيع داراى منافع محلله دوانه

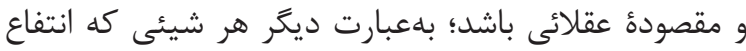

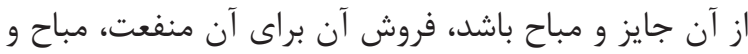

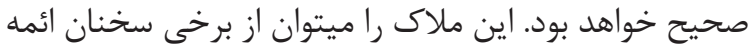
(عليهمالسلام) نيز برداشت كرد كه در اينجا به به بعضى از از آنها بـ آنها

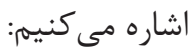

ا. در فقه، خونى است كه موقع بريدن ركى از حيوانى با قوت و شدت خارج شود.
را هم شامل مى شود؛ از طرف ديخر ايشان خريسدوفروش ميته

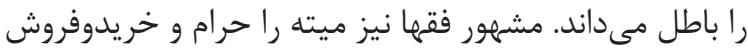

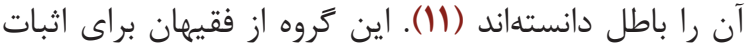

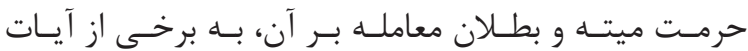

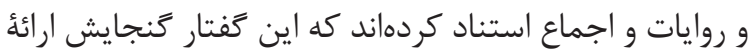
آن ادله را ندارد (•r، •(1). دليل جهارم: بطلان خريدوفروش اشياى نجس

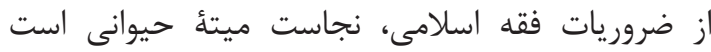

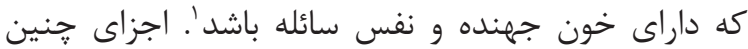

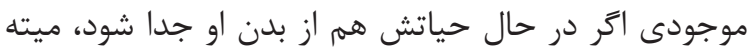

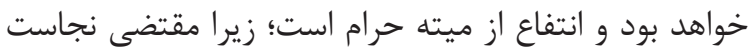

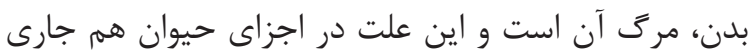

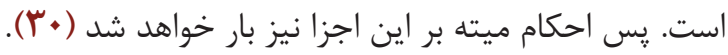

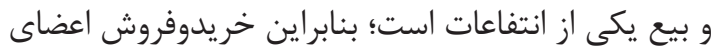

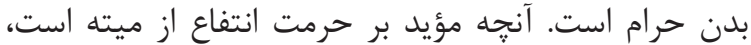

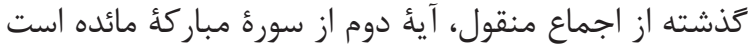

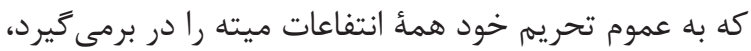

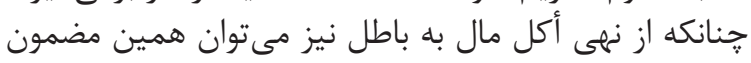

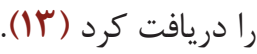
همان كونه كه شيخ انصارى نيز فرموده است، نجاست

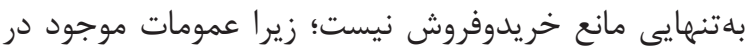

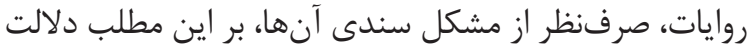

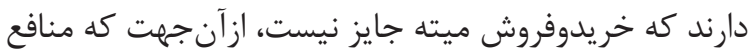

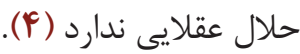

دليل يُجم: ضررى بودن خريدوفروش اعضاى بدن

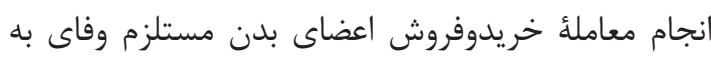

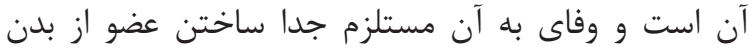

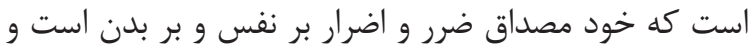

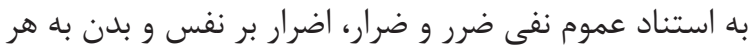

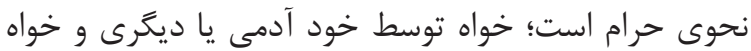

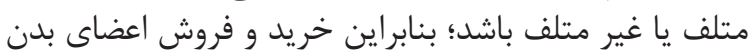

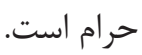

ديدگاه دوم: جواز خريد و فروش اعضاى بدن

الف- استدلالهاى جواز خريد و فروش اعضاى بدن بر مبناى اجتهاد اصولى و مطابق قاعدة اولى، همأ اعمال

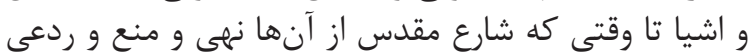

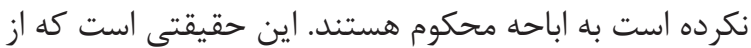

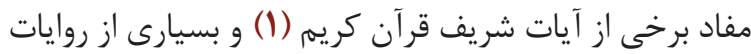

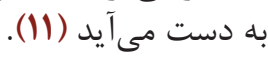

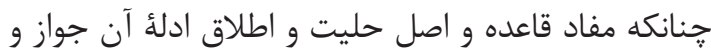

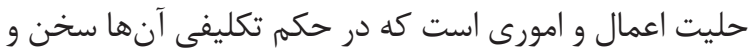

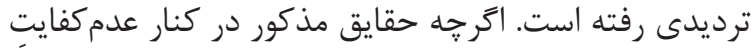

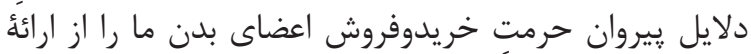

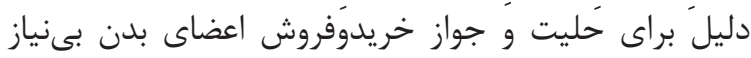

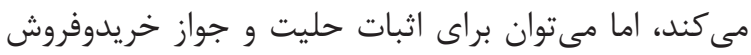
اعضاى بدن به دلايل زير استناد جست: 


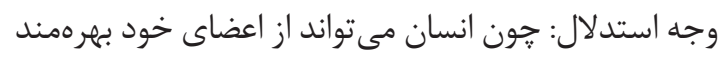

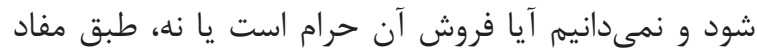

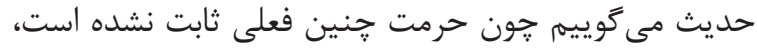

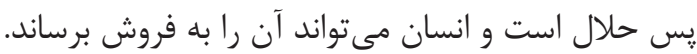

دليل جهارم: بناى عقلا و وجود منفعت محلله

بناى عقلا بر اين است كه مردم بر تن و اموال خود

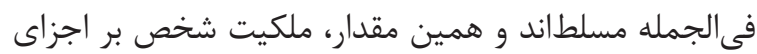

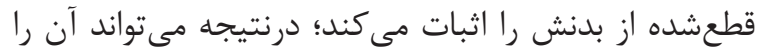

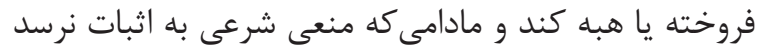

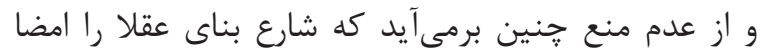

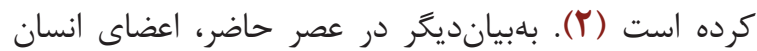

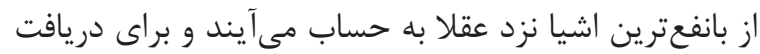

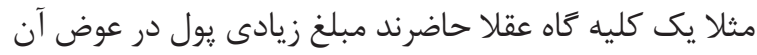

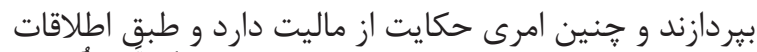

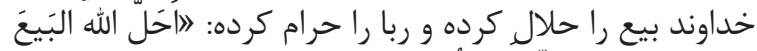

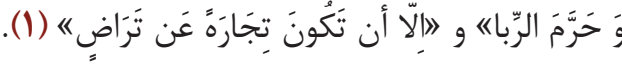

ديدَاه سوم: قابليت فروش بر مبناى حق تصرف

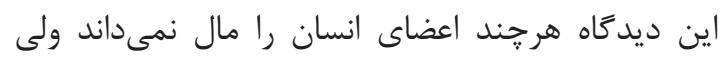

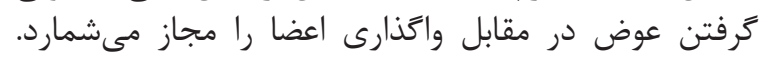

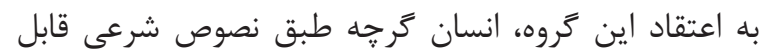

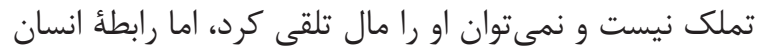

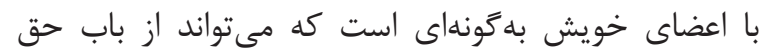

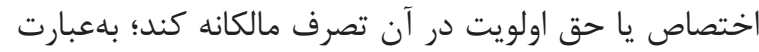

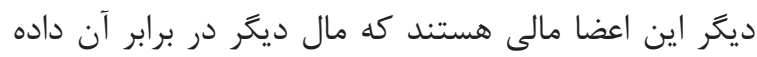

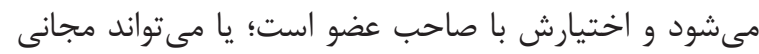

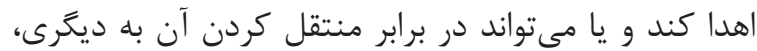

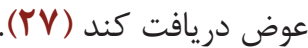

به باور نغارنده مىتوان كفت كه ترفتن مال در مقابل مقابل

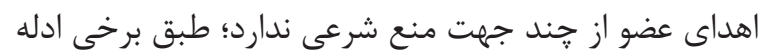

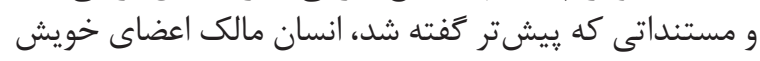

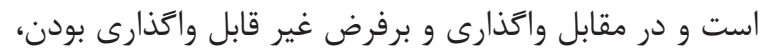

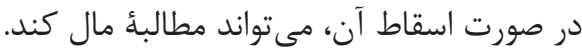

جند نكته دربارءٔ ماليت بر اعضاى بدن

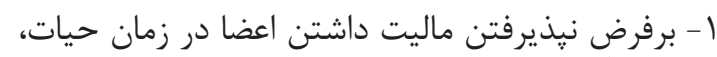

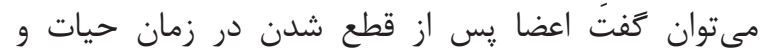

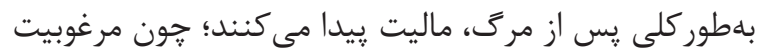

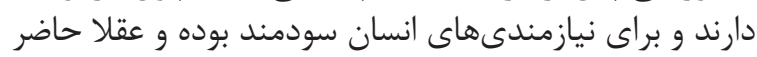
به يرداخت وجه در قبال آن هستند.

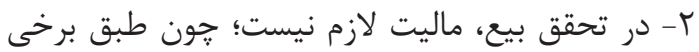

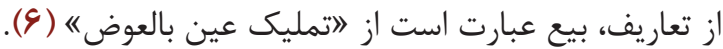

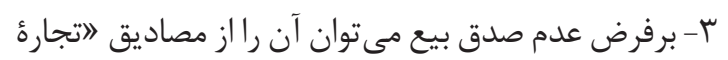

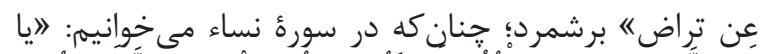

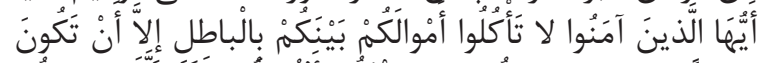

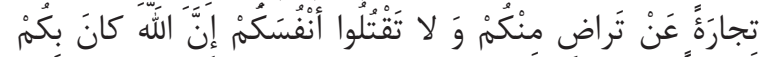

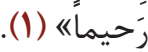

ابن شعبؤ حرانى از امام صادق (عليهالسلام) نقل مى كند:

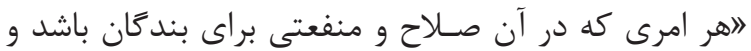

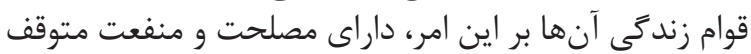

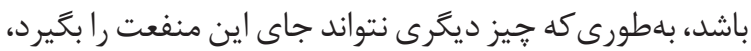

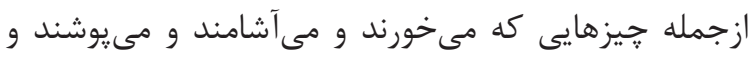

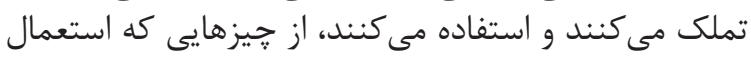

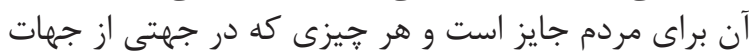

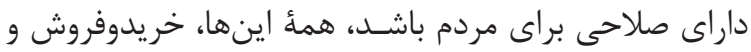

هديه دادن و عاريه دادن آنها جايز استه (1).

جعفر بن محمد مىفرمايد: الهر خوردنى و آشاميدنى آنى

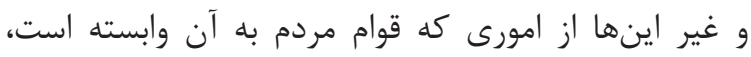

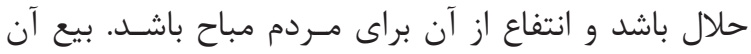

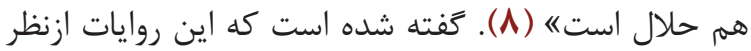

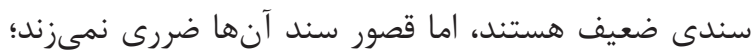

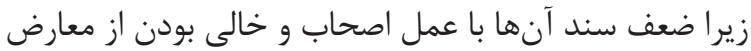
جبران مىشود.

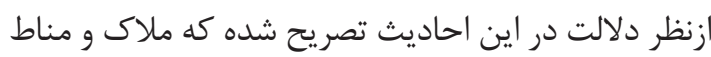

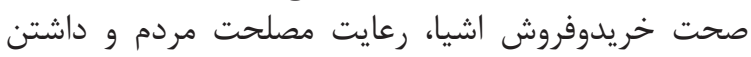

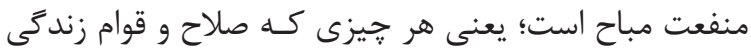

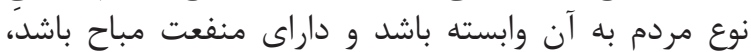

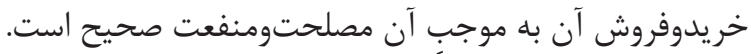

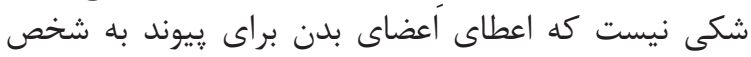

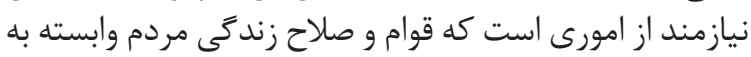

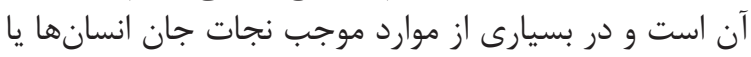

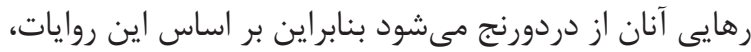

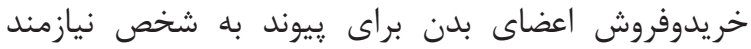

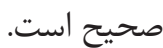

شايان ذكر است كه خريدوفروش عضو در صورتى صحيح

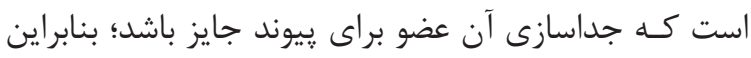

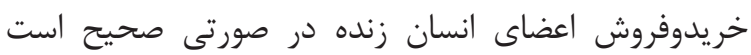

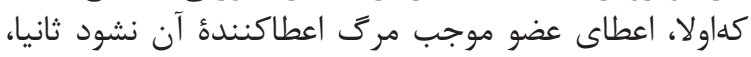

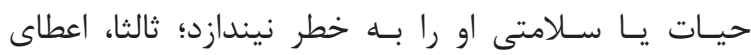

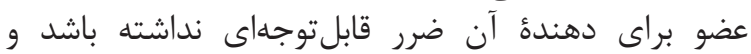

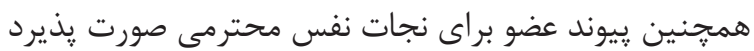

(IF.rQ.rA)

$$
\text { دليل سوم: استناد به اصل عملى }
$$

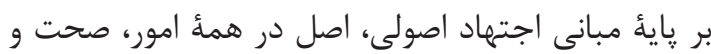

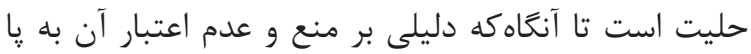

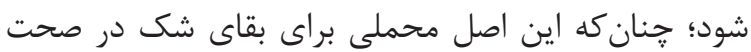

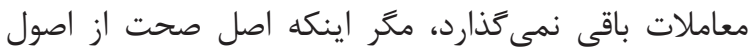

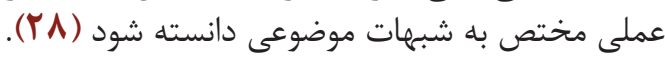

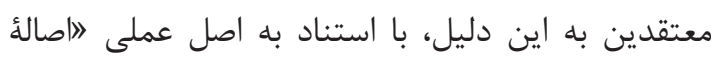

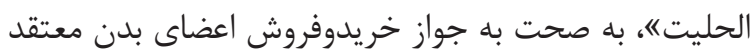

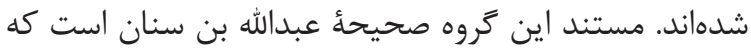

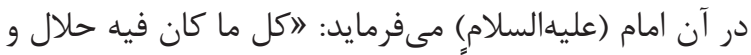

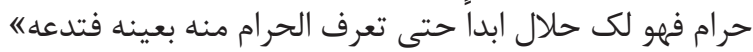




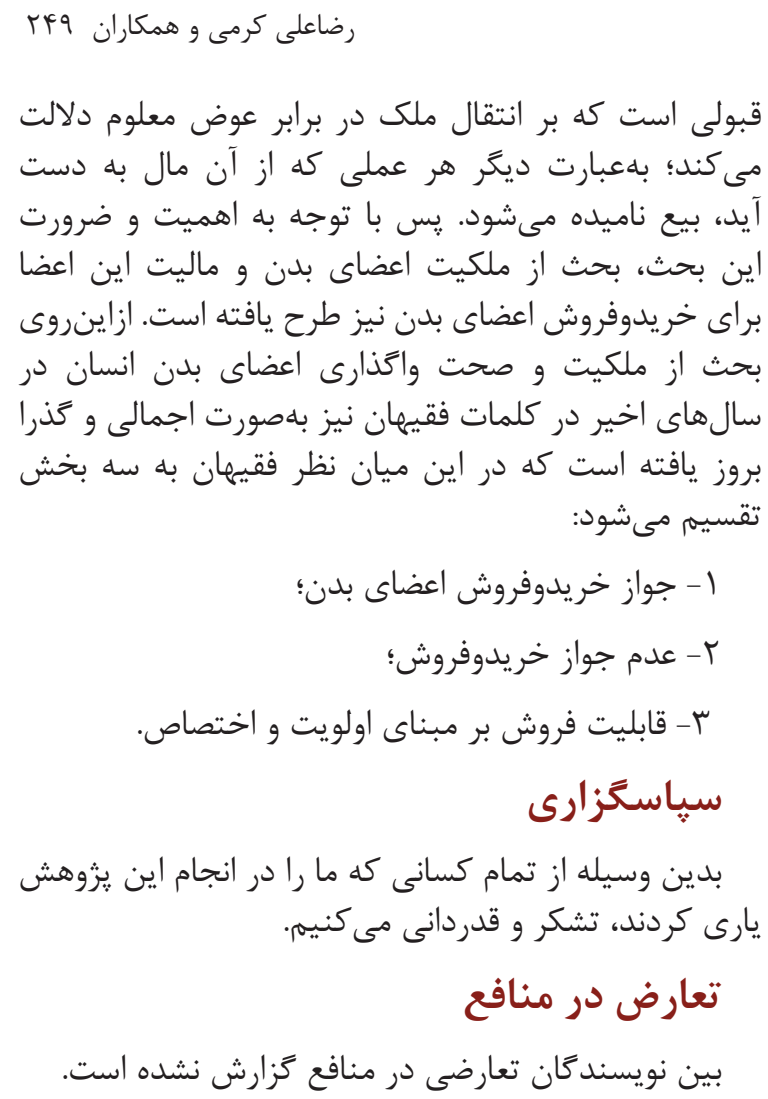

\section{References}

1. The Holy Quran.

2. Aghababaei E. Transplantation of patients from dead patients and brain death.Qom: Islamic Propaganda Office of Qom; 2006.

3. Asefi MM. Brain dead transplant, Ahlbayt jurisprudence ,No 31 .Qom: The Islamic Encyclopedia of Islamic Laws on the Religion of Ahlulbit (AS); 2002.

4. Ansari, Sheikh Morteza BMN. Al Mekasb book. Qom: Islamic Thought Complex; 2001.

5. Bin Manzoor A, Mokram BM. Lesan Al Arab. Beirut: Dar Sader; 1997.

6. Bahr Al Oloum M. Belghat Al Faghih. 4nd ed. Tehran: Maktab Al Sadegh; 1983.

7. Tabrizi MJ. Serat Al Nejat. Qom: Dar Al Sedigheh Al Shahida; 1995.

8. Hor Ameli M. Vasael Al Shia. Qom: Aal Al Beit Institute; 1993.

9. Holly A. Tazkarat Al Foghaha. Qom: Aal Al Beit Institute; 1993.

10. Holly A. Ghavaed Al Ahkaam. Qom: Islamic Publishers Office; 2007.

11. Holly A. Montahi Al Matlab. Qom: Aal Al Beit Institute; 1991.

12. Rohani MS. Fegh'h Al Masael Al Mostahdese.

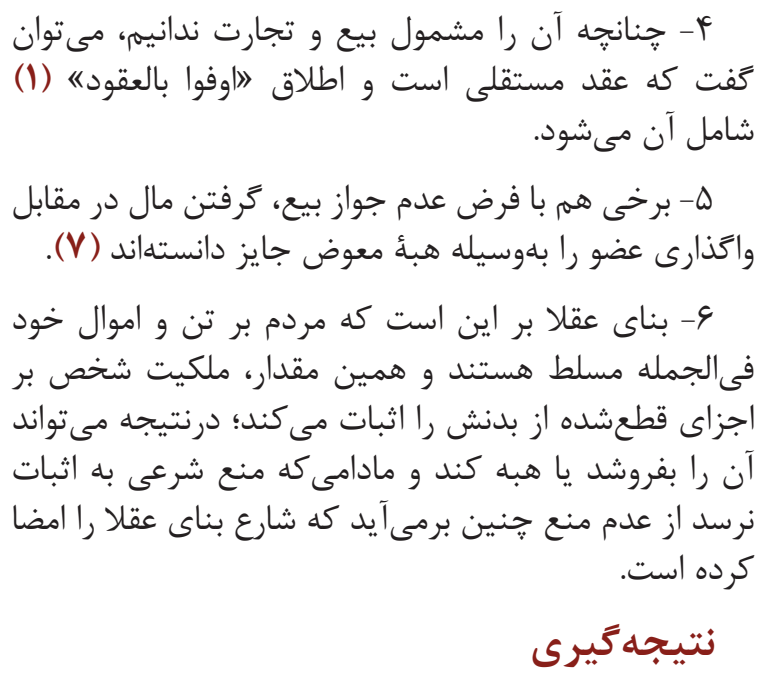

Qom: Hadise Del Publishers; 2005.

13. Khoie SA. Mesbah Al Foghahe. Qom: Ansarian; 1996.

14. Khamenei SA. Resalat Ojobe Al Estefta'at. Tehran: Elahi; 2002.

15. Khomeini SR. Al Bea Book. Tehran: Institute for the Setting up of Imam Khomeini Works; 1943.

16. Khomeini SR. Tahrir Al Vasileh. Volume 2. Tehran: Institute for the Setting up of Imam Khomeini Works; 1942.

17. Sonboholi, Borhanodin M. Islamic Sharia law in transplantation of human organs. Beirut: The Islamic Baath; 1987.

18. Sharafodin A. Legal provisions for medical business. Kuwait: National Council; 1983.

19. Toosi AM. Tahzib Al Ahkaam. 3nd ed. Tehran: Islamic Book House; 2016.

20. Toosi AM. Al Mabsoot. 2nd ed. Tehran: The Razavi Library; 2009.

21. Tabataba'I Hakim SM. Mostamak Al Orvat Al Vosghi. Qom: The Ayatollah Marashi Najafi Library; 1984.

22. Amid H. Amid dictionary. 5nd ed. Tehran: Amir Kabir; 1984.

23. Mohseni MA. Al Fegh'h Masael Tabieh. Qom: 
Islamic Propaganda Office of Qom; 2004.

24. Mohseni MA. Islam and medicine and issues of the jurisprudence of Ja'fari. Qom: Boostan Book; 2012.

25. Fazel Lankarani M. Jame Al Masael. Qom: Meysam Temar; 1998.

26. Fayoumi A. Al Mesbah Al Monir. Qom: Dar Al Hojreh; 1994.

27. Mo'men Ghomi M. "Speech on Transformation and Transplantation of Members", Ahlul-Bayt Fellowship. Encyclopedia of Islamic jurisprudence on the religion of the Ahl al-Bayt (AS). 1997;2(7)
28. Makarem Shirazi N. The jurisprudence. Qom: The publication of Amir Al-Momenin School: 1993.

29. Makarem Shirazi N. The jurisprudence. Qom: Imam Ali bin Abi Talib School: 2001.

30. Najafi MH. Jawaher Al - Kalam in explaining the laws of Islam. 3en ed. Beirut: Islamic Library; 1989.

31. Khomeini SR. "The role of time and place in ijtihad" in: The collection of works of Imam Khomeini's jurisprudential congress. Qom: Institute for the Setting up of Imam Khomeini Works; 1996. 